\title{
CRYSTALLINE ACCOMMODATION LAW EXPLAINS THE CRYSTALLINE STRUCTURE OF MATERIALS
}

\author{
Tarek El Ashram \\ 1-Physics Department, College of Science, Port Said University, Port Said, Egypt \\ 2-Physics Department, College of Science, Jazan University, Jazan, KSA \\ E-mail: tnelashram@gmail.com
}

\begin{abstract}
All crystalline materials crystallize in one of seven crystalline systems which have different shapes and sizes. Why crystalline materials take particular forms of crystals and what make the atoms arrange themselves in these forms. Actually, until now there is no well defined law can account for the crystalline structure of materials. Here we show that the crystalline accommodation law, which is theoretically derived and experimentally verified, can explain the crystalline structure of all types of phases. This law is derived directly from the quantum conditions on the free electrons Fermi gas inside the crystal. The new law relates both the volume of Fermi sphere $V_{F}$ and volume of Brillouin zone $V_{B}$ to the valence electron concentration VEC as, $\frac{V_{F}}{V_{B}}=\boldsymbol{n} \frac{\boldsymbol{V} \boldsymbol{C} C}{2}$ for all crystalline systems and phases, where $n$ is the number of atoms per lattice point or primitive cell. Also because of this law, we introduce the occupied electronic quantum states notation (OEQS), which determine the number of occupied zones in the valence band.
\end{abstract}

\section{Indexing terms/Keywords}

Fermi sphere, Brillouin zone, Valence electron concentration, Crystal Systems, Primitive Cell, Hume-Rothery rules, crystalline accommodation law, OEQS notation.

\section{Academic Discipline And Sub-Disciplines}

Physics, Materials Physics.

\section{SUBJECT CLASSIFICATION}

Crystal Structure.

\section{TYPE (METHOD/APPROACH)}

Theoretical, Experimental and Calculations.

\section{INTRODUCTION}

All crystalline materials crystallize in one of seven crystalline systems which have different shapes and sizes. Why crystalline materials take particular forms of crystals and what make the atoms arrange themselves in these forms. Actually, until now there is no well defined law can account for the crystalline structure of materials. The first attempt to answer this question was initiated by Hume Rothery rules and his coworkers [1] formulated in 1926. These rules include solid solubility rules and electron concentration rule. Solubility rules account for the solid solubility in alloys and include; the atomic size factor, the electrochemical effect and the relative valency effect. Electron concentration rule states that at particular value of valence electron concentration ratio (VEC), intermetallic compounds are formed and have the same crystal structure. These compounds are termed electron compounds or Hume-Rothery compounds and do not obey the valency laws of chemistry. They are divided into three categories according to the value of $V E C$ as the following; VEC = $3 / 2 \beta$-brass (bcc), $V E C=21 / 13 \gamma$-brass (complex cubic) and $V E C=7 / 4 \varepsilon$-brass (cph).

The intermediate phases, which formed in alloys, are of three types; electrochemical compounds, electron compounds and size-factor compounds. Electrochemical compounds obey the valency laws of chemistry and are formed when one element is electropositive and the other is electronegative. Size-factor compounds are formed when the difference in atomic diameter is appreciable. Hume-Rothery electron concentration rule accounts only for the electron compounds not for electrochemical or size-factor compounds. In 1936, Mott and Jones [2] could successfully interpret the Hume-Rothery electron concentration rule in terms of the contact of the Fermi sphere with the set of Brillouin zone planes specific to a given phase. This has come to be known as the Fermi surface-Brillouin zone interaction, FsBz. They proposed that the stability of given phase is enhanced, when the Fermi sphere touches the relevant Brillouin zone planes, leading to the so-called matching condition or interference condition $2 k_{F}=|\boldsymbol{G}|$, where $2 k_{F}$ is the Fermi sphere diameter and $|\boldsymbol{G}|$ is the magnitude of the reciprocal lattice vector corresponding to the relevant Brillouin zone planes. Mizutani and coworkers [3-12] have developed a technique to extract the FsBz interaction based on first-principle FLAPW (full potential linearized augmented plane wave) electronic structure calculations. The FLAPW were performed for the $\mathrm{Ag}_{5} \mathrm{Li}_{8}$ gamma brass and it is found that the Hume-Rothery stabilization mechanism fails for this compound and proposed a new stability mechanism, in which the unique gamma brass structure can effectively lower the band-structure energy by forming heavily populated bonding states near the bottom of $\mathrm{Ag}-4 \mathrm{~d}$ band [7]. In addition, the FLAPW- Fourier analysis led to formulation of new Hume-Rothery electron concentration rule [13] based on the interference condition. The new rule can cover a wider 
range of alloys than the empirical Hume-Rothery rule, which was validated only for noble metal alloys. Actually, the new rule also cannot account for all crystalline phases. The failure of Hume Rothery rule and the new rule comes from including $|\boldsymbol{G}|$ into the rule, because $|\boldsymbol{G}|$ is not fixed for any given structure and varies with the direction.

The term accommodation law is first introduced in this paper. It originates from the work of Tarek El Ashram $[14,15]$ as a new condition for crystalline phase formation and stability. Crystalline accommodation here means the capability of a crystal to adapt its structure to accommodate the valence electrons in the allowed quantum electronic states i.e. obey the accommodation law. This law is derived directly from the quantum conditions on the free electrons Fermi gas inside the crystal and it is not an assumption [15]. The crystalline accommodation law relates the volume of Fermi sphere $V_{F}$ and the volume of Brillouin zone $V_{B}$ to the valence electron concentration ratio $V E C$ as; $\frac{\boldsymbol{V}_{\boldsymbol{F}}}{\boldsymbol{V}_{\boldsymbol{B}}}=\boldsymbol{n} \frac{\boldsymbol{V} \boldsymbol{E} \boldsymbol{C}}{\mathbf{2}}$. Where $n$ is the number of atoms per lattice point or primitive cell and VEC ratio is defined as; the number of the outermost interactive electrons shared in bonding divided by the number of the interacting atoms. The left hand side of this law can be determined experimentally since $\boldsymbol{V}_{\boldsymbol{F}}$ is given by, $\boldsymbol{V}_{\boldsymbol{F}}=\frac{\mathbf{4}}{\mathbf{3}} \boldsymbol{\pi} \boldsymbol{k}_{\boldsymbol{F}}^{\mathbf{3}}$ and $\boldsymbol{k}_{\boldsymbol{F}}$ is the Fermi electron wave vector and can be calculated from Fermi energy as, $\boldsymbol{E}_{\boldsymbol{F}}=\frac{\hbar^{2} \boldsymbol{k}_{\boldsymbol{F}}^{2}}{2 m}$, which can be measured experimentally. In addition, $k_{F}$ can be calculated theoretically from the electron concentration as; $\boldsymbol{k}_{F}=\left(\frac{3 \pi^{2} N}{V}\right)^{\frac{1}{3}}$, here $N / V$ is the number of valence electrons per unit volume. The volume of Brillouin zone $\boldsymbol{V}_{\boldsymbol{B}}$ is given by; $\boldsymbol{V}_{\boldsymbol{B}}=\frac{\mathbf{8} \boldsymbol{\pi}^{\mathbf{3}}}{\boldsymbol{V}_{\boldsymbol{p}}}$, here $V p$ is the volume of the primitive cell, which can be determined experimentally from the XRD data. The right hand side of the law is calculated theoretically from the number of atoms per lattice point $n$ and the valence electron concentration ratio VEC. Therefore, we aim to verify experimentally the crystalline accommodation law and confirm its validity in explaining the crystalline structure for pure elements and different types of compounds.

\section{CALCULATION}

\subsection{EXPERIMENTAL VERIFICATION OF CRYSTALLINE ACCOMMODATION LAW}

The experimental XRD data is obtained from [16] and the experimental data for $E_{F}$ is obtained from [17]. For $\mathrm{Cu}$ (Cubic, Fm $\overline{3} \mathrm{~m}$ ) the volume of primitive cell is given by; $V_{P}=a^{3} / 4, a=3.615 \AA$, this gives for $V_{P}=11.8104 \AA^{3}$ and for $V_{B}$ $=21.0026 \AA^{-3} . E_{F}=6.81 \mathrm{eV}$, this gives for $k_{F}=1.3369 \AA^{-1}$ from which $V_{F}=10.0088 \AA^{-3}$, therefore $V_{F} / V_{B}=0.50037$. Now let us calculate $n V E C / 2$, for $C u$ we have only one atom per lattice point $n=1$ and $V E C=1$, therefore $n V E C / 2=0.5$ which is in a good agreement with the experimental calculated value for $V_{F} / V_{B}$. By the same method of calculation, we get the same result for Gold $(\mathrm{Au})$, silver $(\mathrm{Ag})$ and Aluminum $(\mathrm{Al})$ elements (see Table 1).

Table 1. Experimental verification of crystalline accommodation law.

\begin{tabular}{|c|c|c|c|c|c|c|c|c|c|c|}
\hline Element & VEC & $\begin{array}{l}\text { System } \\
\text { S.G. }\end{array}$ & $\mathrm{n}$ & $\begin{array}{c}E_{F}(t h) \\
e V\end{array}$ & $\begin{array}{c}E_{F}(e x) \\
e V\end{array}$ & $\begin{array}{ll}V_{B} \\
\AA^{-3} \\
\end{array}$ & $\begin{array}{ll}V_{F} \\
\AA^{-3} \\
\end{array}$ & $V_{F} / V_{B}$ & $\mathrm{nVEC} / 2$ & Diff. \\
\hline $\mathrm{Au}$ & 1 & $\begin{array}{l}\text { Cubic } \\
\text { Fm } \overline{3} \mathrm{~m}\end{array}$ & 1 & 5.52 & 5.57 & 14.6132 & 7.4039 & 0.5066 & 0.5 & 0.0066 \\
\hline $\mathrm{Ag}$ & 1 & $\begin{array}{l}\text { Cubic } \\
\text { Fm } \overline{3} m\end{array}$ & 1 & 5.48 & 5.23 & 14.550 & 6.7367 & 0.4630 & 0.5 & 0.0370 \\
\hline $\mathrm{Cu}$ & 1 & $\begin{array}{l}\text { Cubic } \\
\text { Fm } \overline{3} \mathrm{~m}\end{array}$ & 1 & 7.04 & 6.81 & 21.0026 & 10.0088 & 0.50037 & 0.5 & 0.00037 \\
\hline $\mathrm{Zn}$ & 2 & $\begin{array}{c}\text { Hexagonal } \\
\mathrm{P} 6_{3} / \mathrm{mmc}\end{array}$ & 2 & 9.39 & 9.44 & 8.1521 & 16.3343 & 2.0036 & 2.0 & 0.0036 \\
\hline Al & 3 & $\begin{array}{l}\text { Cubic } \\
\text { Fm } \overline{3} \mathrm{~m}\end{array}$ & 1 & 11.66 & 11.65 & 14.9401 & 22.3970 & 1.4991 & 1.5 & 0.0009 \\
\hline Sn & 4 & $\begin{array}{c}\text { Tetragonal } \\
14_{1} / \text { amd }\end{array}$ & 2 & 9.99 & 9.82 & 4.5854 & 17.3315 & 3.7797 & 4.0 & 0.2203 \\
\hline
\end{tabular}

For $Z n$ (Hexagonal, $\mathrm{P}_{3} / \mathrm{mmc}$ ) the volume of primitive cell is given by; $V_{P}=a^{2} c \sqrt{\mathbf{3}} / 2, a=2.665 \AA c=4.947$ this gives for $V_{P}=30.4275 \AA^{3}$ and for $V_{B}=8.1521 \AA^{-3} . E_{F}=9.44 \mathrm{eV}$ this gives for $k_{F}=1.5740 \AA^{-1}$ from which $V_{F}=16.3343 \AA^{-3}$, therefore $V_{F} / V_{B}=2.0036$. Now let us calculate $n V E C / 2$ for $\mathrm{Zn}$, we have two atoms per lattice point $n=2$ and $V E C=2$, therefore $n V E C / 2=2$ which is in a good agreement with the experimental calculated value for $V_{F} / V_{B}$. (see Table 1). For $\beta$-Sn (Tetragonal, $14_{1} /$ amd) the volume of primitive cell is given by; $V_{P}=a^{2} c / 2, a=5.831 \AA c=3.182$ this gives for $V_{P}=54.0948$ $\AA^{3}$ and for $V_{B}=4.5854 \AA^{-3} . E_{F}=9.82 \mathrm{eV}$ this gives for $k_{F}=1.6054 \AA^{-1}$ from which $V_{F}=17.3315 \AA^{-3}$, therefore $V_{F} / V_{B}=$ 3.7797. Now let us calculate $n V E C / 2$ for $\beta$-Sn, we have two atoms per lattice point $n=2$ and $V E C=4$, therefore $n V E C / 2=$ 4 which is in a good agreement with the experimental calculated value for $V_{F} / V_{B}$. (see Table 1 ). 


\subsection{THE VALIDITY OF CRYSTALLINE ACCOMMODATION LAW FOR INTERMEDIATE AND COMPLEX PHASES}

Actually, there is no experimental data available for $\boldsymbol{E}_{F}$ for intermetallic compounds, however we can see from Table 1 that the experimental and theoretical values of $\boldsymbol{E}_{F}$ are nearly the same. Therefore we will determine the value of $\boldsymbol{E}_{\boldsymbol{F}}$ theoretically.

\subsubsection{Electrochemical Compounds}

For $\mathrm{NaCl}$ (Cubic, $\mathrm{Fm} \overline{3} \mathrm{~m}$ ) the volume of primitive cell is given by; $V_{P}=a^{3} / 4, a=5.642 \AA$ this gives for $V_{P}=44.8992$ $\AA^{3}$ and for $V_{B}=21.0026 \AA^{-3} . E_{F}=11.546 \mathrm{eV}$ this gives for $k_{F}=1.7408 \AA^{-1}$ from which $V_{F}=22.0984 \AA^{-3}$, therefore $V_{F} / V_{B}=$ 4.000073. Now let us calculate $n V E C / 2$ for $\mathrm{NaCl}$, we have two atoms per lattice point $n=2$ and $V E C=(1 \times 1+1 \times 7) / 2=4$, therefore $n V E C / 2=4$ which is in a good agreement with the experimental calculated value for $V_{F} / V_{B}$ (see Table 2).

Table 2. The validity of crystalline accommodation law for different types of compounds.

\begin{tabular}{|c|c|c|c|c|c|c|c|c|c|}
\hline Compound & VEC & $\begin{array}{c}\text { System } \\
\text { S.G. }\end{array}$ & $\mathbf{n}$ & $\begin{array}{c}E_{F} \\
(e V)\end{array}$ & $\begin{array}{c}V_{B} \\
\left(\AA^{-3}\right)\end{array}$ & $\begin{array}{c}V_{F} \\
\left(\AA^{-3}\right)\end{array}$ & $V_{F} / V_{B}$ & nVEC/2 & Diff. \\
\hline \multicolumn{10}{|c|}{ 1. Electrochemical Compounds } \\
\hline $\mathrm{NaCl}$ & 4 & $\begin{array}{l}\text { Cubic } \\
\text { Fm } \overline{3} \mathrm{~m}\end{array}$ & 2 & 11.546 & 5.5245 & 22.0984 & 4.000073 & 4 & .00007 \\
\hline $\mathrm{Mg}_{2} \mathrm{Sn}$ & $8 / 3$ & $\begin{array}{l}\text { Cubic } \\
\text { Fm } \overline{3} \mathrm{~m}\end{array}$ & 3 & 8.045 & 3.2133 & 12.8532 & 4.000012 & 4 & .00001 \\
\hline $\mathrm{Mg}_{2} \mathrm{~Pb}$ & $8 / 3$ & $\begin{array}{l}\text { Cubic } \\
\text { Fm } \overline{3} \mathrm{~m}\end{array}$ & 3 & 7.918 & 3.1375 & 12.550 & 4.00000 & 4 & 0 \\
\hline $\mathrm{CaF}_{2}$ & $16 / 3$ & $\begin{array}{l}\text { Cubic } \\
\text { Fm } \overline{3} \mathrm{~m}\end{array}$ & 3 & 19.549 & 6.0856 & 48.6851 & 8.000056 & 8 & .00005 \\
\hline \multicolumn{10}{|c|}{ 2. Size-factor Compounds } \\
\hline $\mathrm{MgCu}_{2}$ & $4 / 3$ & $\begin{array}{l}\text { Cubic } \\
\mathrm{Fd} \overline{3} \mathrm{~m}\end{array}$ & 6 & 7.428 & 2.8509 & 11.4038 & 4.0001 & 4 & .0001 \\
\hline $\mathrm{AgBe}_{2}$ & $5 / 3$ & $\begin{array}{l}\text { Cubic } \\
\mathrm{Fd} \overline{3} \mathrm{~m}\end{array}$ & 6 & 10.745 & 3.9680 & 19.8403 & 5.000076 & 5 & .00007 \\
\hline $\mathrm{Au}_{2} \mathrm{Bi}$ & $7 / 3$ & $\begin{array}{l}\text { Cubic } \\
\text { Fd } \overline{3} m\end{array}$ & 6 & 8.427 & 1.9687 & 13.7811 & 7.00013 & 7 & .00013 \\
\hline $\mathrm{BaMg}_{2}$ & 2 & $\begin{array}{c}\text { Hexagonal } \\
\mathrm{P} 6_{3} / \mathrm{mmc}\end{array}$ & 12 & 5.511 & 0.6073 & 7.2881 & 12.00083 & 12 & .00083 \\
\hline $\mathrm{MgZn}_{2}$ & 2 & $\begin{array}{c}\text { Hexagonal } \\
\mathrm{P}_{3} / \mathrm{mmc}\end{array}$ & 12 & 8.779 & 1.221 & 14.6524 & 12.00038 & 12 & .00038 \\
\hline \multicolumn{10}{|c|}{ 3. Electron Compounds } \\
\hline CuZn & $3 / 2$ & $\begin{array}{l}\text { Cubic } \\
\text { Pm } \overline{3} \mathrm{~m}\end{array}$ & 2 & 8.727 & 9.6818 & 14.5227 & 1.50000 & 1.5 & 0 \\
\hline $\mathrm{CuBe}$ & $3 / 2$ & $\begin{array}{l}\text { Cubic } \\
\text { Pm } \overline{3} \mathrm{~m}\end{array}$ & 2 & 10.381 & 12.5603 & 18.8405 & 1.500011 & 1.5 & .00011 \\
\hline $\mathrm{AgCd}$ & $3 / 2$ & $\begin{array}{l}\text { Cubic } \\
\operatorname{Pm} \overline{3} \mathrm{~m}\end{array}$ & 2 & 6.832 & 6.7066 & 10.0599 & 1.500003 & 1.5 & .00003 \\
\hline $\mathrm{Cu}_{5} \mathrm{Zn}_{8}$ & $\begin{array}{c}21 / 1 \\
3\end{array}$ & $\begin{array}{l}\text { Cubic } \\
1 \overline{4} 3 \mathrm{~m}\end{array}$ & 26 & 8.873 & 0.7089 & 14.8882 & 21.0018 & 21 & .0018 \\
\hline $\mathrm{Cu}_{9} \mathrm{Al}_{4}$ & $\begin{array}{c}21 / 1 \\
3 \\
\end{array}$ & $\begin{array}{l}\text { Cubic } \\
\mathrm{P} \overline{4} 3 \mathrm{~m}\end{array}$ & 52 & 9.234 & 0.3763 & 15.8061 & 42.0041 & 42 & .0041 \\
\hline $\mathrm{Ag}_{5} \mathrm{Cd}_{8}$ & $\begin{array}{c}21 / 1 \\
3\end{array}$ & $\begin{array}{l}\text { Cubic } \\
1 \overline{4} 3 \mathrm{~m}\end{array}$ & 26 & 7.0184 & 0.4987 & 10.4729 & 21.0000 & 21 & 0 \\
\hline $\mathrm{AgZn}_{3}$ & $7 / 4$ & $\begin{array}{c}\text { Hexagonal } \\
\mathrm{P} 6_{3} / \mathrm{mmc}\end{array}$ & 4 & 13.652 & 8.1195 & 28.4145 & 3.4995 & 3.5 & .0005 \\
\hline $\mathrm{AgCd}_{3}$ & $7 / 4$ & $\begin{array}{c}\text { Hexagonal } \\
\mathrm{P} 6_{3} / \mathrm{mmc}\end{array}$ & 4 & 11.530 & 6.3007 & 22.0523 & 3.4999 & 3.5 & .0001 \\
\hline $\mathrm{AuCd}_{3}$ & $7 / 4$ & $\begin{array}{c}\text { Hexagonal } \\
\mathrm{P6}_{3} / \mathrm{mmc}\end{array}$ & 24 & 7.096 & 0.5070 & 10.6476 & 21.0012 & 21 & .0012 \\
\hline $\mathrm{Ag}_{5} \mathrm{Li}_{8}$ & 1 & $\begin{array}{l}\text { Cubic } \\
1 \overline{4} 3 \mathrm{~m}\end{array}$ & 26 & 5.1763 & 0.5102 & 6.6333 & 13.00013 & 13 & .00001 \\
\hline
\end{tabular}




\subsubsection{Size-Factor Compounds}

For $A u_{2} B i$ (Cubic, Fd $\overline{3} \mathrm{~m}$ ) the volume of primitive cell is given by; $V_{P}=a^{3} / 4, a=7.958 \AA$ this gives for $V_{P}=$ $125.9945 \AA^{3}$ and for $V_{B}=1.9687 \AA^{-3} . E_{F}=8.427 \mathrm{eV}$ this gives for $K_{F}=1.4873 \AA^{-1}$ from which $V_{F}=13.7811 \AA^{-3}$, therefore $V_{F} / V_{B}=7.00013$. Now let us calculate $n V E C / 2$ for $\mathrm{Au}_{2} \mathrm{Bi}$, we have six atoms per lattice point $n=6$ and $V E C=(2 \times 1+1 \times 5) / 3$ $=4$, therefore $n V E C / 2=7$ which is in a good agreement with the experimental calculated value for $V_{F} / V_{B}$ (see Table 2).

\subsubsection{Elecron Compounds}

For VEC $=3 / 2$, let us take CuZn (Cubic, $P m \overline{3} m$ ) the volume of primitive cell is given by; $V_{P}=a^{3}, a=7.958 \AA$ this gives for $V_{P}=25.6201 \AA^{3}$ and for $V_{B}=9.6818 \AA^{-3} . E_{F}=8.727 \mathrm{eV}$ this gives for $k_{F}=1.5135 \AA^{-1}$ from which $V_{F}=14.5227 \AA^{-3}$, therefore $V_{F} / V_{B}=1.500009$. Now let us calculate $n V E C / 2$ for CuZn, we have 2 atoms per lattice point $n=2$ and $V E C=$ $(1 \times 1+1 \times 2) / 2=3 / 2$, therefore $n V E C / 2=1.5$ which is in a good agreement with the experimental calculated value for $V_{F} / V_{B}$ (see Table 2). For $V E C=21 / 13$, let us take $\mathrm{Cu}_{9} \mathrm{Al}_{4}$ (Cubic, $P \overline{4} 3 \mathrm{~m}$ ) the volume of primitive cell is given by; $V_{P}=a^{3}, a=$ $8.7027 \AA$ this gives for $V_{P}=659.1162 \AA^{3}$ and for $V_{B}=0.3763 \AA^{-3} . E_{F}=9.2345 \mathrm{eV}$ this gives for $k_{F}=1.5568 \AA^{-1}$ from which $V_{F}=15.8061 \AA^{-3}$, therefore $V_{F} / V_{B}=42.0041$. Now let us calculate $n V E C / 2$ for $\mathrm{Cu}_{9} \mathrm{Al}_{4}$, we have 52 atoms per lattice point $n$ $=52$ and $V E C=(9 \times 1+4 \times 3) / 13=21 / 13$, therefore $n V E C / 2=42$ which is in a good agreement with the experimental calculated value for $V_{F} / V_{B}$ (see Table 2). For $V E C=7 / 4$, let us take $\mathrm{AgZn}_{3}$ (Hexagonal, $\mathrm{P} 6_{3} / \mathrm{mmc}$ ) the volume of primitive cell is given by; $V_{P}=a^{2} c \sqrt{3} / 2, a=2.8227 \AA, c=4.4274 \AA$ this gives for $V_{P}=30.5498 \AA^{3}$ and for $V_{B}=8.1195 \AA^{-3}$. $E_{F}=$ $13.65 \mathrm{eV}$ this gives for $k_{F}=1.8930 \AA^{-1}$ from which $V_{F}=28.4183 \AA^{-3}$, therefore $V_{F} / V_{B}=3.4995$. Now let us calculate $n V E C / 2$ for $\mathrm{AgZn}_{3}$, we have 4 atoms per lattice point $n=4$ and $V E C=(1 \times 1+3 \times 2) / 4=7 / 4$, therefore $n V E C / 2=3.5$, which is in a good agreement with the experimental calculated value for $V_{F} / V_{B}$ (see Table 2). For complex phase $\mathrm{Ag}_{5} \mathrm{Li}_{8}$ (Cubic, $1 \overline{4} 3 \mathrm{~m}$ ) the volume of primitive cell is given by; $V_{P}=a^{3} / 2, a=9.9066 \AA$ this gives for $V_{P}=486.1204 \AA^{3}$ and for $V_{B}=0.5102 \AA^{-3}$. $E_{F}=$ $5.1763 \mathrm{eV}$ this gives for $\boldsymbol{k}_{F}=1.1656 \AA^{-1}$ from which $\boldsymbol{V}_{F}=6.6333 \AA^{-3}$, therefore $V_{F} / V_{B}=13.00013$. Now let us calculate $n V E C / 2$ for $\mathrm{Ag}_{5} \mathrm{Li}_{8}$, we have 26 atoms per lattice point $\boldsymbol{n}=26$ and $V E C=(5 \times 1+8 \times 1) / 13=13 / 13=1$, therefore $n V E C / 2=13$, which is in a good agreement with the experimental calculated value for $V_{F} / V_{B}$ (see Table 2).

\section{RESULTS AND DISSCUSION}

It is clear from Table 1 that the experimental $\left(\frac{V_{F}}{V_{B}}\right)$ and theoretical $\left(\boldsymbol{n} \frac{V E C}{2}\right)$ values are very consistent. This is a conclusive evidence on the validity of cryastalline accommodation law. The success of this law comes from including $V_{\boldsymbol{B}}$ which is fixed for any given structure instead of $|G|$ which is not fixed and varies with the direction, into the law. Here we can not account for all elements and compounds but actually, this law can explaine any crystal structure. A very important note is that this law gives the number of occupied electronic quantum states (OEQS). This number as we see from Table 1 is either integer or half integer which indicates that the state may be filled or half filled. Every Brillouin zone accommodates only one state and every state accommodates only two electrons of opposite spins, if it is filled, or one electron, if it is half filled. This also indicates the validity of this law, for example let us take $\mathrm{Cu} ; \frac{V_{F}}{V_{\boldsymbol{B}}}=\boldsymbol{n} \frac{\boldsymbol{V} \boldsymbol{C} \boldsymbol{C}}{2}=0.5$ this means for $\mathrm{Cu}$ we have only the first zone half filled. Let us represent the number of occupied electronic quantum state notation (OEQS) for $\mathrm{Cu}$ as $1 \mathrm{Bz}^{0.5}$. By the same way we can represent the OEQS for $\mathrm{Zn}$ as $2 \mathrm{Bz}$ (two filled zones), Al as $2 \mathrm{Bz}^{.05}$ (two zones, the first is filled and the second is half filled) and Sn as 4Bz (four filled zones, seeTable 3 ).

Table 3. The OEQS for some elements

\begin{tabular}{|c|c|c|c|c|c|}
\hline Element & VEC & $\begin{array}{l}\text { System } \\
\text { S.G. }\end{array}$ & $\mathbf{n}$ & $\mathrm{nVEC} / 2$ & OEQS \\
\hline $\mathrm{Au}$ & 1 & $\begin{array}{l}\text { Cubic } \\
\text { Fm } \overline{3} m\end{array}$ & 1 & 0.5 & $1 \mathrm{Bz}^{0.5}$ \\
\hline $\mathrm{Ag}$ & 1 & $\begin{array}{l}\text { Cubic } \\
\text { Fm } \overline{3} m\end{array}$ & 1 & 0.5 & $1 \mathrm{Bz}^{0.5}$ \\
\hline $\mathrm{Cu}$ & 1 & $\begin{array}{l}\text { Cubic } \\
\text { Fm } \overline{3} m\end{array}$ & 1 & 0.5 & $1 \mathrm{Bz}^{0.5}$ \\
\hline Zn & 2 & $\begin{array}{l}\text { Hexagonal } \\
P 6_{3} / \mathrm{mmc}\end{array}$ & 2 & 2.0 & $2 \mathrm{Bz}$ \\
\hline Al & 3 & $\begin{array}{l}\text { Cubic } \\
\text { Fm } \overline{3} \mathrm{~m}\end{array}$ & 1 & 1.5 & $2 \mathrm{Bz}^{0.5}$ \\
\hline Sn & 4 & $\begin{array}{l}\text { Tetragonal } \\
\text { 14,/amd }\end{array}$ & 2 & 4.0 & $4 \mathrm{Bz}$ \\
\hline
\end{tabular}

For compounds, it is clear from Table 2 that the experimental $\left(\frac{V_{F}}{V_{B}}\right)$ and theoretical $\left(\boldsymbol{n} \frac{V E C}{2}\right)$ values are very consistent. Therefore the crystal accommodation law can explain the crystalline structure for different types of compounds including 
complex structures. The OEQS for these compounds are represented in Table 4. For example the $\mathrm{OEQS}_{\mathrm{S}}$ for $\mathrm{Cu}_{9} \mathrm{Al}_{4}$ is $42 \mathrm{Bz}$ (42 filled zones), these zones are overlapped, because there is no gaps in the valence band.

Table 4. The OEQS for some compounds.

\begin{tabular}{|c|c|c|c|c|c|}
\hline Compound & VEC & $\begin{array}{l}\text { System } \\
\text { S.G. }\end{array}$ & $\mathbf{n}$ & nVEC/2 & OEQS \\
\hline $\mathrm{NaCl}$ & 4 & $\begin{array}{l}\text { Cubic } \\
\text { Fm } \overline{3} \mathrm{~m}\end{array}$ & 2 & 4 & $4 \mathrm{Bz}$ \\
\hline $\mathrm{Mg}_{2} \mathrm{Sn}$ & $8 / 3$ & $\begin{array}{l}\text { Cubic } \\
\text { Fm } \overline{3} \mathrm{~m}\end{array}$ & 3 & 4 & $4 \mathrm{Bz}$ \\
\hline $\mathrm{Mg}_{2} \mathrm{~Pb}$ & $8 / 3$ & $\begin{array}{l}\text { Cubic } \\
\text { Fm } \overline{3} \mathrm{~m}\end{array}$ & 3 & 4 & $4 \mathrm{Bz}$ \\
\hline $\mathrm{CaF}_{2}$ & $16 / 3$ & $\begin{array}{l}\text { Cubic } \\
\text { Fm } \overline{3} \mathrm{~m}\end{array}$ & 3 & 8 & $8 \mathrm{Bz}$ \\
\hline $\mathrm{MgCu}_{2}$ & $4 / 3$ & $\begin{array}{l}\text { Cubic } \\
\text { Fd } \overline{3} m\end{array}$ & 6 & 4 & $4 \mathrm{Bz}$ \\
\hline $\mathrm{AgBe}_{2}$ & $5 / 3$ & $\begin{array}{l}\text { Cubic } \\
\text { Fd } \overline{3} m\end{array}$ & 6 & 5 & $5 B z$ \\
\hline $\mathrm{Au}_{2} \mathrm{Bi}$ & $7 / 3$ & $\begin{array}{l}\text { Cubic } \\
\text { Fd } \overline{3} \mathrm{~m}\end{array}$ & 6 & 7 & 7Bz \\
\hline $\mathrm{BaMg}_{2}$ & 2 & $\begin{array}{l}\text { Hexagonal } \\
\mathrm{P}_{3} / \mathrm{mmc}\end{array}$ & 12 & 12 & $12 \mathrm{Bz}$ \\
\hline$M g Z n_{2}$ & 2 & $\begin{array}{l}\text { Hexagonal } \\
\mathrm{P}_{3} / \mathrm{mmc}\end{array}$ & 12 & 12 & $12 \mathrm{Bz}$ \\
\hline CuZn & $3 / 2$ & $\begin{array}{l}\text { Cubic } \\
\operatorname{Pm} \overline{3} \mathrm{~m}\end{array}$ & 2 & 1.5 & $2 B z^{0.5}$ \\
\hline CuBe & $3 / 2$ & $\begin{array}{l}\text { Cubic } \\
\text { Pm } \overline{3} \mathrm{~m}\end{array}$ & 2 & 1.5 & $2 \mathrm{Bz} \mathrm{z}^{0.5}$ \\
\hline $\mathrm{AgCd}$ & $3 / 2$ & $\begin{array}{l}\text { Cubic } \\
\text { Pm } \overline{3} \mathrm{~m}\end{array}$ & 2 & 1.5 & $2 \mathrm{Bz}{ }^{0.5}$ \\
\hline $\mathrm{Cu}_{5} \mathrm{Zn}_{8}$ & $21 / 13$ & $\begin{array}{l}\text { Cubic } \\
1 \overline{4} 3 \mathrm{~m}\end{array}$ & 26 & 21 & $21 \mathrm{Bz}$ \\
\hline $\mathrm{Cu}_{9} \mathrm{Al}_{4}$ & $21 / 13$ & $\begin{array}{l}\text { Cubic } \\
\mathrm{P} \overline{4} 3 \mathrm{~m}\end{array}$ & 52 & 42 & $42 \mathrm{Bz}$ \\
\hline $\mathrm{Ag}_{5} \mathrm{Cd}_{8}$ & $21 / 13$ & $\begin{array}{l}\text { Cubic } \\
1 \overline{4} 3 \mathrm{~m}\end{array}$ & 26 & 21 & 21Bz \\
\hline $\mathrm{AgZn}_{3}$ & $7 / 4$ & $\begin{array}{l}\text { Hexagonal } \\
\mathrm{P}_{3} / \mathrm{mmc}\end{array}$ & 4 & 3.5 & $4 \mathrm{Bz}^{0.5}$ \\
\hline $\mathrm{AgCd}_{3}$ & $7 / 4$ & $\begin{array}{l}\text { Hexagonal } \\
\mathrm{PG}_{3} / \mathrm{mmc}\end{array}$ & 4 & 3.5 & $4 B z^{0.5}$ \\
\hline $\mathrm{AuCd}_{3}$ & $7 / 4$ & $\begin{array}{l}\text { Hexagonal } \\
\mathrm{P}_{3} / \mathrm{mmc}\end{array}$ & 24 & 21 & 21Bz \\
\hline $\mathrm{Ag}_{5} \mathrm{Li}_{8}$ & 1 & $\begin{array}{l}\text { Cubic } \\
1 \overline{4} 3 \mathrm{~m}\end{array}$ & 26 & 13 & $13 \mathrm{Bz}$ \\
\hline
\end{tabular}

\section{CONCLUSION}

In conclusion, the crystalline accommodation law, $\frac{V_{F}}{V_{B}}=\boldsymbol{n} \frac{\boldsymbol{V} \boldsymbol{C} C}{2}$, which is theoretically derived and experimentally verified, can successfully account for the crystalline structure of all types of crystalline phases. According to this law, the crystal adapts its structure in such a way to accommodate the valence electrons into the allowed electronic quantum states. Because of this law, we introduce the occupied electronic quantum states notation (OEQS) for different types of crystalline phases to account for the number of filled zones in the valence band. 


\section{REFERENCES}

1. Hume-Rothery W., Researches on the nature, properties, and conditions of formation of intermetallic compounds, with special reference to certain compounds of tin-I-V. J. Inst. Met. 35, (1926) 295-361.

2. Mott, N.F.; Jones, H. The Theory of the Properties of Metals and Alloys; Clarendon Press: Oxford, UK, 1936; Dover Publications Inc.: New York, NY, USA, (1958).

3. U. Mizutani. Hume-Rothery Rules for Structurally Complex Alloy Phases, CRC Press/Taylor \& Francis Group, Boca Raton, FL, (2010).

4. R. Asahi, H. Sato, T. Takeuchi and U. Mizutani. Verification of Hume-Rothery electron concentration rule in $\mathrm{Cu}_{5} \mathrm{Zn}_{8}$ and $\mathrm{Cu}_{9} \mathrm{Al}_{4} \mathrm{Y}$ brasses by ab initio FLAPW band calculations. Phys. Rev. B 71 (2005).

5. R. Asahi, H. Sato, T. Takeuchi and U. Mizutani. Interpretion of Hume-Rothery electron concentration rule in the $\mathrm{T}_{2} \mathrm{Zn}_{11},(\mathrm{~T}=\mathrm{Ni}, \mathrm{Pd}, \mathrm{Co}$, and Fe) $\gamma$ brasses based on the first principle FLAPW calculations. Phys. Rev. $B 72$ (2005).

6. U. Mizutani, R. Asahi, H. Sato and T. Takeuchi. Mediated resonance effect of the vanadium $3 d$ states on phase stability in the $\mathrm{Al}_{8} \mathrm{~V}_{5} \mathrm{Y}$-brass studied by first-principles FLAPW and LMTO-ASA electronic structure calculations. Phys. Rev. B 74 (2006).

7. U. Mizutani, R. Asahi, H. Sato, T. Noritake and T. Takeuchi. Failure of the Hume-Rothery stabilization mechanism in the $\mathrm{Ag}_{5} \mathrm{Li}_{8}$ gamma-brass studied by first-principles FLAPW electronic structure calculations. J. Phys.: Condens. Matter 20 (2008).

8. U. Mizutani, R. Asahi, T. Takeuchi, H. Sato, O.Y. Kontsevoi and A.J. Freeman, e/a determination for the transition metal element $\mathrm{TM}$ in $\mathrm{Al}-\mathrm{Cu}-\mathrm{TM}-\mathrm{Si}(\mathrm{TM}=\mathrm{Fe}$ and $\mathrm{Ru}$ ) approximants and B2-compounds by means of the FLAPW-Fourier method, Z. Kristallogr. 224, (2009)

9. 17.U. Mizutani, Y. Kondo, Y. Nishino, M. Inukai, M. Feuerbacher and H. Sato, Fermi surface-Brillouin-zoneinduced pseudogap in $\mathrm{y}-\mathrm{Mg}_{17} \mathrm{Al}_{12}$ and a possible stabilization mechanism of $\beta-\mathrm{Al}_{3} \mathrm{Mg}_{2}, \mathrm{~J}$. Phys.: Condens. Matter $22(2010)$.

10. U. Mizutani, M. Inukai and H. Sato, Hume-Rothery stablization mechanism and d-states- mediated Fermi surface Brillouin zone interaction in structurally complex alloys. Phil. Mag. 91, (2011) 2536.

11. M. Inukai, K. Soda, H. Sato and U. Mizutani, Electronic structure of $A g_{5} Z n_{8}, A g_{9} I_{4}$ and $M_{3} I n$ gamma-brasses studied by FLAPW band calculations. Phil. Mag. 91, (2011) 2543.

12. M. Inukai, E.S. Zijlstra, H. Sato and U. Mizutani, Origin of DOS pesudogap Hume-Rothery stabilization mechanism in $\mathrm{RT} \mathrm{Al}_{48} \mathrm{Mg}_{64} \mathrm{Zn}_{48}$ and $\mathrm{Al}_{84} \mathrm{Li}_{52} \mathrm{Cu}_{24}$ 1/1-1/1-1/1 approximants. Phil. Mag. 91, (2011) 4247.

13. U. Mizutania, M. Inukaiby, H. Satoc and E.S. Zijlstrad, Hume-Rothery stabilization mechanism and e/a determination in Ml-type Al-Mn, Al-Re, Al-Re-Si, Al-Cu-Fe-Si and Al-Cu-Ru-Si 1/1-1/1-1/1 approximants - a proposal for a new Hume-Rothery electron concentration rule. Philosophical Magazine, 92, No. 13, (2012) 16911715.

14. Tarek El-Ashram. Theoretical modification of Hume Rothery condition of phase stability in a good agreement with experimental data. J. of Advances in Physics. 9, No.3, (2015) 2503.

15. T. El Ashram. A New Condition of Formation and Stability of All Crystalline Systems in a Good Agreement with Experimental Data. J. of Advances in Physics, 11. No 4, (2015) 3224.

16. Selected Powder Diffraction Data for Education \& Training, Search Manual and Data Cards, JCPDS, International Cent

17. er For Diffraction Data, Editor-in-Chief, William Frank McClune, 1601 Park Lan, Swarthmore, PA 19081-2389, JCPDS, printed in U.S.A. (1988)

18. Prashant Kumar Tripathi, Gangadharan K. V. Computer interface to accurately determination of Fermi energy and Fermi temperature of materials. International Journal of Computer Applications, 38, No. 2, (2012) 0975-8887. 


\section{Author' biography with Photo}

Prof. Dr. Tarek El Ashram

Professor of materials physics

1- Physics Department, College of Science,

Port Said University, Port Said, Egypt

2- Physics Department, College of Science, Jazan University, Jazan, KSA

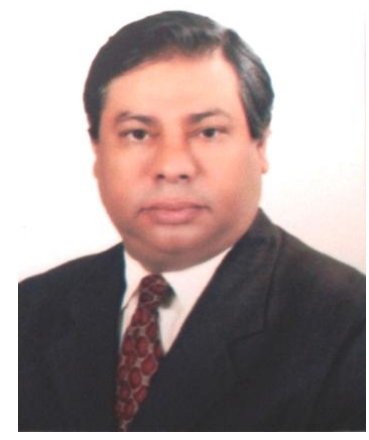

\section{(c) (7)}

This work is licensed under a Creative Commons Attribution 4.0 International License.

DOI : 10.24297/jap.v13i8.6295 